\title{
ADAPTIVE MECHANISM FOR MASTERING KAPITAL AND IMPROVING INTERNATIONAL STABILITY
}

\author{
Tsyganov V.V. ${ }^{1}$, Bagamaev R.A. ${ }^{2}$ and Gurlev I.V. ${ }^{3}$
}

\author{
${ }^{1}$ Leading Researcher of the Institute of Control Sciences, Profsoyuznaja Str., 65, \\ Moscow,117342,RUSSIA,E-mail:bbc@ipu.rssi.ru. \\ ${ }^{2}$ President of the commercial bank "VITAS', \\ Eniseyskaja,22, Moscow, 108432, RUSSIA,E-mail:R.Bagamaev@vitasbank.ru \\ ${ }^{3}$ Researcher of the Institute of Control Sciences, Profsoyuznaja Str., \\ 65, Moscow, 117342, RUSSIA, E-mail: bbc@ipu.rssi.ru.
}

\begin{abstract}
Adaptive mechanism is used to control the process of the corporation or state development by means of the investments. New paradigm about capital and brain drain between corporations and countries deals with mastering capital emphasizes the advancements that occur in both the development and practice of decision making about investment attractiveness of the business and the investment climate in the country. The theorem about sufficient conditions of the definite direction of the capital flow between two businesses of the corporation or countries is given. Copyright (C) 2005 IFAC
\end{abstract}

Keywords: Investments, adaptive mechanism, control, corporation, state, capital drain.

\section{INTRODUCTION}

The technological changes are created by high technologies (high-tech) and appropriate investments. They produce both positive and negative effects of the evolution of the corporation or state. First of all, the advanced systems that are in existence, as well as those being built, can be used effectively to help staff to realize the benefits that are possible with the present-day high technology. From the other side, potential of high-tech now is often accumulated in a major leading corporation or states. They supply high-tech all over the world. To provide new hightech it is necessary to realize $R \& D$, know-how, investments, etc. That needs appropriate intellectual and financial resources. The prices of high-tech goods and services are mainly not competitive prices because of the monopoly on the results of $R \& D$ and know-how. From the other side, price of traditional goods, provided by corporations of the developing countries, are under strong competitions. For this reason investigations and investments in high-tech are in most of cases preferable. Financial and intellectual resources drain from developing to leading corporations or states. The result of this capital and brain drain is the lack of financial and intellectual potentials in developing businesses and countries. It becomes more and more difficult to provide R\&D, know-how, investments and new hightech. Therefore technological development produces economical rupture between leading and developing corporations or states. That provides likelihood of crisis, and as a consequence tensions between different businesses. This provides obstacles to the realization of a more stable set of domestic, regional and international relations. 


\section{ADAPTIVE MECHANISM TO MANAGE CAPITAL FLOW}

One of the important ways to diminish a gap between leading and developing businesses is to minimize capital and brain drain. Let us consider the problem of capital drain. The concept of control mechanism derived by Tsyganov [1990a] is applied to manage capital flows between leading and developing states (or corporations). The mathematical approach used the modified model of the developing active element described by Burkov and Tsyganov [1986]. Under consideration is the corporation (or state) provides two business processes. Potential of each business rises in accordance with the equation:

$$
q_{i t+1}=A_{i} q_{i t}+B_{i} u_{i t}, \quad q_{i 0}=q^{*}
$$

where $q_{i t}$ - potential (value of capital stock) of the $i$ th business, $i=1,2, \quad u_{i t}$-investments in the $i$-th business in period $t, A_{i}$ and $B_{i}$ - positive coefficients, $t$ - number of period, $t=0,1, \ldots T-1$. The profit of each business is:

$$
z_{i t}=C_{i} q_{i t}
$$

where $C_{i}$ is profit per unit $q_{i}, C_{i}>0, i=1,2$. The total profit of the corporation (or state) is:

$$
z_{t}=z_{1 t}+z_{2 t}=C_{1} q_{1 t}+C_{2} q_{2 t}
$$

Total investments of the corporation (or state) $u_{t}$ are equal to the total profit:

$$
u_{t}=u_{1 t}+u_{2 t}=z_{t}
$$

The purpose of allocation of these investments is to maximize present value of the corporation:

$$
\mathrm{W}=\sum_{\mathrm{i}=1}^{2} \sum_{\mathrm{t}=0}^{\mathrm{T}-1} \rho \mathrm{Z}_{\mathrm{it}} \underset{\mathrm{u}_{\mathrm{t}}}{\longrightarrow} \max
$$

where $\rho$ is a discount rate, $\rho<1, T$ - horizon for business planning (farseeing) of the corporation. THEOREM. Total investments in period $t, 1 \leq t \leq T-1$,

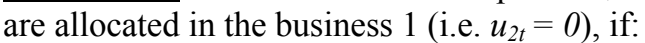

$$
\begin{gathered}
I_{1 t}>I_{2 t}, I_{i t}=A_{i} B_{i}\left[1-\left(\rho C_{i}\right)^{t}\right] /\left(1-\rho C_{i}\right), \\
i=\overline{1,2} .
\end{gathered}
$$

This theorem gives sufficient conditions about the definite direction of the capital flow between two businesses. It determines matrix of the investment attractiveness:

$$
\begin{gathered}
I_{i t}=A_{i} B_{i}\left[1-\left(\rho C_{i}\right)^{t}\right] /\left(1-\rho C_{i}\right), \quad i=\overline{1,2}, \\
t=\overline{1, T-1 .}
\end{gathered}
$$

With the aid of the matrix of the investment attractiveness measurement means and criteria for monitoring of the capital flow can be found. If matrix of the investment attractiveness satisfied the condition of the theorem then it should be income of the investments in business 1 , and outcome of the capital from business 2 in the period $t, t=1, \ldots, T-1$. Statement. The business 1 is called as the capital attractor if all the investments are allocated in this business:

$$
u_{2 t}=0, \quad t=1, \ldots, T-1
$$

CONSEQUENCE 1 . The business 1 is the capital attractor if:

$$
I_{1 t}>I_{2 t}, \quad i=\overline{1,2}, \quad t=\overline{1, T-1} .
$$

If matrix of the investment attractiveness satisfied the condition of consequence 1 then it should be stable income of the investments in business 1, and outcome of the capital from business 2 in each period $t, t=1, \ldots, T-1$.

\section{PARAMETERS OF THE INVESTMENT ATTRACTIVENESS}

In this approach matrix of the investment attractiveness $I_{i}=\left(I_{i 1}, \ldots, I_{i T-1}\right)$ is the vectors indicator of the investment attractiveness of the $i$-th business in the corporation (or state). Let us determine parameters of the investment attractiveness of the $i$-th business. Suppose that $q_{i t}$-value of capital stock; $z_{i t}$-income. Then $A_{i}=1-\alpha_{i}$, where $\alpha_{i}-$ coefficient of the depreciation of capital stock; $B_{i}=E_{i}$ $\left(1+s_{i}\right)$, where $E_{i}$ - efficiency of investment, $s_{i}-$ coefficient of the support of investment in $i$-th business. Profit

$C_{i}=\left[\left(1-h_{i}\right)\left(1+u_{i}\right) P_{i} v_{i}-3_{i}\right] G_{i}-\alpha_{i}$

where: $P_{i}$ - world market price, $h_{i}$ - income tax, $u_{i}-$ custom tax, $v_{i}$ - rate of exchange of $i$-th currency; $3_{i}\left(m_{i}\right)$ - expenses per unit of the product of the the $i$ th business: $m_{i}=\left\{m_{i l}, l=\overline{1, L}\right\}$ - tariffs on heat, electricity, energy, transport etc.; $G_{i}-$ efficiency of capital stock;

$$
D_{i}=1-r_{i}\left(1-a_{i} \alpha_{i} C_{i}^{-1}\right)
$$

$a_{i}$ - depreciation tax credit, $0 \leq a_{i} \leq 1, r_{i}$ - net income (profit) tax.

So matrix of the investment attractiveness is the function of the parameters both the domestic and the international regimes such as prices, efficiency of investment, taxes, trade and customs rules etc. Changing some of these parameters it is possible to determine direction of capital flow between businesses. The set of these parameters may be used to establish desirable direction of capital flow is called investment climate. Let us consider the statement of the investment climate.

\section{INVESTMENT CLIMATE}

Formally investment climate $(K)$ is the set of the parameters used by the Center of the economic system to choose desirable direction of the capital flow between businesses. This flow is directed to the most attractive business. In this approach matrix of 
the investment attractiveness $I_{i}=\left(I_{i 1}, \ldots, I_{i T}-1\right)$ is the vectors indicator of the investment attractiveness of the $i$-th business. So the set of parameters of matrix of the investment attractiveness $I_{i}=\left(I_{i 1}, \ldots, I_{i T-1}\right)$ determines the investment climate:

$$
\begin{gathered}
K=\left\{\alpha_{i}, a_{i}, h_{i}, r_{i}, s_{i}, u_{i}, v_{i}, m_{i}=\left\{m_{i}, l=\overline{1, L}\right\},\right. \\
i=\overline{1,2}\}
\end{gathered}
$$

So investment climate $K$ is the vector function of the parameters both the domestic and the international regimes such as prices, efficiency of investment, taxes, trade and customs rules etc. Let us consider the corporation operating in different branches of economy. Then business in branch, were investment climate is better, has biggest investment attractiveness. In this business income of investments takes place, etc.

\section{RUSSIA IN CONDITIONS OF THE LIBERAL GLOBALIZATION}

Consider the problem of capital drain between the countries. Matrix of the investment attractiveness $I_{i}=\left(I_{i 1}, \ldots, I_{i T-1}\right)$ may be used to manage capital flows between leading and developing countries. Let us consider the corporation including two businesses operating in two countries. Then in country, were investment climate is better, income of investments takes place, etc. Under consideration is the effectiveness of the mechanism of liberal globalization $\sum^{G}$, which includes:

1. United market price: $P_{i}=P$.

2. United coefficient of the depreciation of capital stock: $\alpha_{i}=\alpha$.

3. United efficiency of investment: $E_{i}=E$.

4. United investment climate $K^{G}$ :

$$
\begin{gathered}
\alpha_{i}=\alpha_{i}, a_{i}=a, h_{i}=h, r_{i}=r, s_{i}=s, u_{i}=u, v_{i}=1, m_{i l}=m_{l}, \\
l=\overline{1, L}, i=\overline{1,2} .
\end{gathered}
$$

Russian academician L.V. Milov proved such regularity: corresponding to the coldest climate in the world and long distances for transportation in Russia means that the expenses in the Russian agriculture is biggest then in the other country:

$$
3_{1}\left(m_{1}\right)>3_{2}\left(m_{2}\right)
$$

There index 1 corresponds to Russia and index 2 corresponds to any other country of the world. Academicians Milov also showed that efficiency of the capital stock $G_{l}$ in the Russian agriculture is the smallest in the world:

$$
G_{1}<G_{2} \text {. }
$$

Substituting (4) and (5) in (3) and using the conditions 1-4 of the mechanism of the liberal globalization $\Sigma^{G}$, it is easy to obtain:

$$
C_{1}<C_{2}
$$

That means that the Russian agriculture had the smallest profit in the world under the mechanism of the liberal globalization $\Sigma^{\mathrm{G}}$. Denote that under the condition 2-4 of the mechanism of the liberal globalization $\sum^{\mathrm{G}}$

$$
A_{1}=A_{2}, B_{1}=B_{2}
$$

Substituting (6) and (7) in the matrix of the investment attractiveness $(2)$, it is easy to obtain:

$$
\begin{gathered}
I_{1 t}<I_{2 t}, I_{i t}=A B\left[1-\left(\rho C_{i}\right)^{t}\right] /\left(1-\rho C_{i}\right), \\
i=\overline{l, 2 .}
\end{gathered}
$$

Substituting inequality (8) in the conditions (1) of the theorem, we obtain

CONSEQUENCE 2. Total investments in the agriculture are allocated beyond the Russia agriculture:

$$
u_{1 t}=0,1 \leq t \leq T-1 .
$$

In this approach condition (8) shows the inequality of the vectors indicator of the investment attractiveness of the agriculture in the Russia and in the other country. As a result the capital flies from the Russia agriculture to the most attractive foreign agriculture.

Russian academician A.P.Parshev proved the same regularity in the Russia industry. He showed that corresponding to the coldest climate and long distances in Russia the expenses in the Russian industry is the biggest in the world:

$$
3_{l}\left(m_{1}\right)>3_{2}\left(m_{2}\right)
$$

and the efficiency of capital stock $G_{l}$ in the Russian industry is the smallest in the world:

$$
G_{1}<G_{2} \text {. }
$$

There index 1 corresponds to Russia and index 2 corresponds to any other country of the world. Substituting (9) and (10) in (3) and using the conditions 1-4 of the mechanism of the liberal globalization $\Sigma^{\mathrm{G}}$, it is easy to obtain:

$$
C_{1}<C_{2}
$$

That means that the profit in the Russian industry is smaller than abroad under the mechanism of the liberal globalization $\Sigma^{G}$. Denote that under the condition 2-4 of the mechanism of the liberal globalization $\Sigma^{G}$

$$
A_{1}=A_{2}, B_{1}=B_{2} \text {. }
$$

Substituting (11) and (12) in the matrix of the investment attractiveness (2), it is easy to obtain:

$$
\begin{gathered}
I_{1 t}<I_{2 t}, I_{i t}=A B\left[1-\left(\rho C_{i}\right)^{t}\right] /\left(1-\rho C_{i}\right), \\
i=\overline{1,2 .}
\end{gathered}
$$

Substituting inequality (13) in the conditions (1) of the theorem, we obtain

CONSEQUENCE 3. Total industrial investments are allocated beyond the Russia industry:

$$
u_{1 t}=0,1 \leq t \leq T-1 \text {. }
$$

In this approach condition (13) shows the inequality of the investment attractiveness of the industry in the Russia and in the other country. As a result the capital flies from the Russia industry to the most attractive foreign industry.

Matrix of the investment attractiveness $I_{i}=\left(I_{i 1}, \ldots, I_{i T-1}\right)$ is a function of the parameters of the domestic regimes such as prices, efficiency of 
investment, taxes, trade and customs rules etc. For the reasons shown by consequence $2 \& 3$ the Russian government must use special procedures for adjusting appropriate parameters of investment climate to control capital flow from the country.

\section{THE CAPITAL DRAIN AND THE CORPORATION AND STATE REGIMES}

Important indicator is the total quantity of capital drain from the business should be calculated as a difference between outcome and income of the investments in different businesses, branches of economy or countries. This indicator is the function of the matrix of the investment attractiveness parameters both the domestic and the international regimes such as prices, efficiency of investment, taxes, trade and customs rules etc. Information about matrix of the investment attractiveness $I_{i}=\left(I_{i 1}, \ldots, I_{i T-1}\right)$ may provide indication of leading events for various corporation or states that may describe conditions of normal, alert, and emergency operation for various potential trouble spots in the world. Possible courses should be developed for action to resolve situations corresponding to alert and emergency operation. Various possible alternative actions can be explored. Through the use of models, simulations, discussions with knowledgeable experts from both the businesses involved, as well as with third-party experts, it should be possible to get various impressions of what may be the possible outcome of alternative actions. In the adaptive mechanism there are special procedures used for adjusting of the parameters of the corporation or state regimes to control capital flow. For example, Tsyganov [1990b] considered simulation of progressive adaptive mechanisms of multistage negotiation based on the new information technologies. Incentives and motivations for cooperation may be developed. In each of the businesses involved the staff responsible for the decision-making that causes a capital flow can be provided with various incentives for keeping the capital from the flight. In real situations capital and intellectual flows are managed by the special state procedures and mechanisms. They are called by Young [1982] and Krasner [1983] as international regimes. Coates and Seamen [1989] indicate that international regimes are closely linked with domestic political and economical procedures and mechanisms. Total mechanism to control capital and intellectual flows includes both international and domestic regimes. For example, detailed description both these regimes, dealing with capital flows through joint ventures, had been given by Tsyganov [1991a].

\section{CONCLUSION}

Technological changes and investments provide the progress and simultaneously produce rupture between leading and developing businesses, corporations and countries. Provision of ability to manage corporation or state in its dynamics is based on application of control theory. The theorem about sufficient conditions of the definite direction of the capital flow between two businesses determines criteria about decision making in the process of the investments (matrix of the investment attractiveness). This theorem determines also criteria for mastering capital of the corporation or state. With the aid of this theorem measurement means for monitoring investment attractiveness of the business, corporation or state are found. These criteria are the indicators of the investment climate and simultaneously the function of the parameters both the domestic and the international regimes such as prices, efficiency of investment, taxes, trade and customs rules etc. Matrix of the investment attractiveness determines investment climate and also is the function of these parameters. Choosing investment climate it is possible to manage capital flow between different businesses, corporations and countries.

\section{REFERENCES}

Burkov, V.N. and V.V. Tsyganov (1986). Stochastic Mechanisms of the Active System Functioning. In: Preprints of the $2^{\text {nd }}$ IFAC Symposium on Stochastic Control. 1, 259-263. Nauka, Moscow.

Coates, J.F. and S. Seamen (1989). The Relation of Management to Control Technology - Futher Applied Studies in Creative Management of Potential Conflict at International Levels. In: Preprints of the IFAC SWIIS Workshop "International Conflict Resolution Using Systems Engineering”, 47-54, Budapest.

Krasner S. (1983). International Regimes. Cornell University Press, N.-Y.

Tsyganov V.V. (1990a). Modelling of Adaptive Control Mechanism for International Cooperation. In: Report on the Research Workshop "Models and concepts of interdependence between nations". "SovietAmerican Dialogue in the Social Sciences", 74. National Academy Press, Washington, D.C.

Tsyganov, V.V. (1990b). Simulation of Progressive Adaptive Mechanisms of Multistage Negotiations and the New Information Technologies. In: Preprints of the $11^{\text {th }}$ IFAC World Congress. 1, 202-206. Tallinn.

Tsyganov V.V. (1991a). Joint venturing in the USSR. Radianska osvita, Kiev.

Young O.R (1982). Regime Dynamics: The Rise and Fall of International Regimes. International Organizations, 36, 43-52. 